\title{
Severe eosinophilic asthma: from the pathogenic role of interleukin-5 to the therapeutic action of mepolizumab
}

This article was published in the following Dove Press journal:

Drug Design, Development and Therapy

30 October 2017

Number of times this article has been viewed

\author{
Corrado Pelaia' \\ Alessandro Vatrella ${ }^{2}$ \\ Maria Teresa Busceti' \\ Luca Gallelli ${ }^{3}$ \\ Rosa Terracciano ${ }^{3}$ \\ Rocco Savino ${ }^{3}$ \\ Girolamo Pelaia' \\ 'Department of Medical and Surgical \\ Sciences, Section of Respiratory \\ Diseases, University “Magna Græcia” \\ of Catanzaro, Catanzaro, ${ }^{2}$ Department \\ of Medicine, Surgery and Dentistry, \\ Section of Respiratory Diseases, \\ University of Salerno, Salerno, \\ ${ }^{3}$ Department of Health Science, \\ University "Magna Græcia” of \\ Catanzaro, Catanzaro, Italy
}

\begin{abstract}
Mepolizumab is an anti-interleukin-5 (IL-5) humanized monoclonal antibody that has been recently approved as an add-on biological treatment for severe eosinophilic asthma, by both the US Food and Drug Administration (FDA) and the European Medicines Agency (EMA). Moreover, mepolizumab is also currently included within the step 5 of the Global Initiative for Asthma guidelines, as an add-on therapy for severe uncontrolled asthma. The relevant therapeutic benefits detectable in patients with refractory eosinophilic asthma receiving mepolizumab depend on the pivotal pathogenic role played by IL-5 in these subjects. Indeed, IL-5 is the key cytokine responsible for maturation, activation, proliferation, and survival of eosinophils. Therefore, IL-5 represents a strategic molecular target for anti-eosinophilic treatments. By selectively inhibiting the biological actions of IL-5, mepolizumab provides a valuable therapeutic option for patients with severe eosinophilic asthma, refractory to standard treatments including inhaled and even systemic corticosteroids. In particular, the very important advantages linked to the use of mepolizumab in these difficult-to-treat asthmatic individuals have been well documented by several different trials performed worldwide.
\end{abstract}

Keywords: IL-5, severe eosinophilic asthma, mepolizumab

\section{Introduction}

Asthma is a chronic disease of the airways, characterized by recurrent episodes of wheezing, dyspnea, cough, and chest tightness, which is sustained by inflammatory and structural changes responsible for airflow limitation and bronchial hyperresponsiveness to a wide range of environmental stimuli. ${ }^{1,2}$ In particular, asthma can be stratified across several phenotypes and endotypes, featured by distinct clinical and pathobiological expressions, as well as by different responses to pharmacological treatments. ${ }^{3,4}$ Many subjects with asthma are quite well controlled by standard therapies based on inhaled corticosteroids and $\beta_{2}$-adrenergic bronchodilators, to which oral leukotriene inhibitors and inhaled anticholinergics may eventually be added. ${ }^{5,6}$ Nevertheless, some patients with severe asthma need additional biological therapies because, in spite of an optimized standard treatment, they still experience uncontrolled symptoms and recurrent exacerbations, often requiring prolonged courses of oral corticosteroids. It has been well known for a long time that airway eosinophilic inflammation can be associated with either allergic or non-allergic asthma, as well as with severe and fatal disease. ${ }^{7-10}$ In patients with eosinophilic asthma, eosinophils accumulate within the bronchial tract where they release cytotoxic proteins, lipid mediators, cytokines, and chemokines that significantly contribute to airway inflammation and remodeling. ${ }^{11}$
Correspondence: Girolamo Pelaia Department of Medical and Surgical Sciences, Section of Respiratory Diseases, University "Magna Græcia” of Catanzaro, Campus Universitario "S. Venuta",

Viale Europa - Località Germaneto, 88100 Catanzaro, Italy

Tel +39096I 3647302

Fax+39096I 3647193

Email pelaia@unicz.it
Drug Design, Development and Therapy 2017:|| 3|37-3|44

3137

Dovepress f in

http://dx.doi.org// 0.21 477/DDDT.S150656

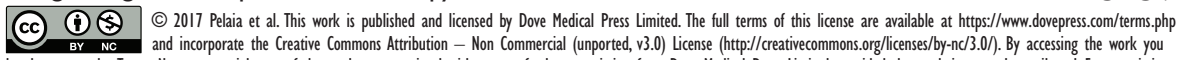
hereby accept the Terms. Non-commercial uses of the work are permitted without any further permission from Dove Medical Press Limited, provided the work is properly attributed. For permission for commercial use of this work, please see paragraphs 4.2 and 5 of our Terms (https://www.dovepress.com/terms.php). 
Eosinophilic asthma is characterized by high eosinophil levels in induced sputum and peripheral blood. Airway eosinophilia can be detected in $>50 \%$ of asthmatic patients, and elevated eosinophil counts are associated with frequent asthma exacerbations, as well as with a high degree of airflow limitation and disease severity. ${ }^{12}$ Hence, given the key role exerted by interleukin-5 (IL-5) in eosinophil biology, including cell maturation in the bone marrow, recruitment to the inflamed tissues, activation, proliferation, and survival, ${ }^{13,14}$ this cytokine is currently a very important molecular target for add-on biological therapies aimed to improve the control of difficult-to-treat eosinophilic asthma. ${ }^{15-20}$

Therefore, based on the above considerations, the aim of this review is to outline the role of IL-5 in eosinophilic asthma and to discuss the clinical effects and the place the anti-IL-5 monoclonal antibody mepolizumab has in asthma therapy.

\section{IL-5 and eosinophilic asthma}

Within the airways of patients with eosinophilic asthma, IL-5 is mainly produced by Th2 cells, group 2 innate lymphoid cells (ILC2), mast cells, natural killer T (NKT) cells, and eosinophils themselves. ${ }^{21-25}$ In allergic asthmatic subjects the bone marrow reacts to allergen challenge by increasing eosinophil production, and in patients manifesting both early and late asthmatic reactions, this event is associated with higher IL-5 mRNA levels than individuals experiencing only immediate bronchial responses. ${ }^{26}$ In addition to the effects induced within the bone marrow, IL-5 also appears to be able to promote eosinophil maturation locally in the airways, as shown by the enhanced amounts of IL-5, eosinophil progenitors, and mature eosinophils detectable in the induced sputum of allergic patients who experience both early and late asthmatic responses. ${ }^{27}$ With regard to the induction of bronchial eosinophilic infiltration and airway hyperresponsiveness, IL-5 exerts synergistic actions with potent eosinophil chemoattractants such as eotaxins 1, 2, and $3 .{ }^{14}$ Moreover, in comparison to control subjects and patients with mild persistent asthma, significantly higher concentrations of IL-5 and eotaxins have been detected in the induced sputum obtained from individuals manifesting acute asthmatic exacerbations. ${ }^{28}$ IL-5 and eotaxins synergize in eliciting eosinophil recruitment within the bronchial tree, especially when exacerbations of asthma occur; this effect is likely due at least in part to the antiapoptotic action exerted by IL-5 on eosinophils. ${ }^{29,30}$ Indeed, IL-5 concentrations in induced sputum resulted to be inversely correlated with the number of eosinophils undergoing apoptosis in patients with exacerbations of asthma, as well as in subjects with stable disease. IL-5 plays a pivotal pathobiologic role also in patients with non-allergic, late-onset eosinophilic asthma. ${ }^{31}$ In such patients ILC2, rather than Th2 cells, are the main cellular source of IL-5. ${ }^{32}$

IL-5 exerts its biological actions via stimulation of the IL-5 receptor expressed by eosinophils and, to a lesser extent, also by basophils. This receptor consists of an IL-5-specific $\alpha$ subunit (IL-5R $\alpha$ ) and a non-specific $\beta$ c chain (Figure 1) that interact with IL-5, interleukin-3 (IL-3), and granulocytemacrophage colony stimulating factor (GM-CSF) ${ }^{33,34}$ In the absence of IL-5, IL-5R $\alpha$ is associated with the intracellular tyrosine kinase Janus kinase (JAK)2, and the $\beta \mathrm{c}$ subunit is complexed with JAK $1 .{ }^{35}$ When IL-5 binds to IL-5R $\alpha$, this interaction triggers the assembly of a functional IL-5R $\alpha-\beta c$ receptor unit that drives the activation of a complex signal transduction network, including several different components. ${ }^{15,36,37}$ In particular, upon IL-5-mediated activation, JAK2 in turn stimulates the transcriptional functions of signal transducers and activators of transcription (STAT)1, 3 , and 5, which increase the expression rates of several genes implicated in eosinophil proliferation such as pim-1 and cyclin D3 (Figure 1). ${ }^{38,39}$ Furthermore, JAK2 cooperates with Lyn and Raf-1 kinases in mediating the antiapoptotic effect induced by IL-5 on eosinophils, resulting in a significant prolongation of their survival. ${ }^{40}$ Raf- 1 also contributes to promote the activation and degranulation of eosinophils. ${ }^{40}$

Within the signaling pathways activated by IL-5, key functions are also exerted by downstream intracellular kinases such as mitogen-activated protein kinases (MAPK) and phosphoinositide 3-kinase (PI3K) (Figure 1). In particular, Raf-1-dependent stimulation of the ERK (extracellular signal-regulated kinases) subgroup of MAPK plays a central role as trigger of $c$-fos gene transcription and eosinophil maturation, proliferation and survival, as well as inducer of leukotriene $\mathrm{C}_{4}$ release. ${ }^{41-44}$ Moreover, the p38 subgroup of MAPK stimulates, also via activation of the transcription factor nuclear factor- $\kappa \mathrm{B}(\mathrm{NF}-\kappa \mathrm{B})$, eosinophil expression of pro-inflammatory cytokines, and eosinophil adhesion and recruitment involved in allergic inflammation. ${ }^{44-46}$ IL-5dependent binding of eosinophils to intercellular adhesion molecule-1 (ICAM-1) is also mediated by PI3K-induced activation of ERK1/2 and protein kinase C (PKC). ${ }^{47}$

Therefore, because of the key functions exerted by IL-5 in eosinophil biology, this cytokine and its receptor are very important molecular targets for the development of biological therapies focused on the management of eosinophilic asthma., ${ }^{2,17}$ Indeed, using murine models of experimental asthma, some preclinical investigations showed that 


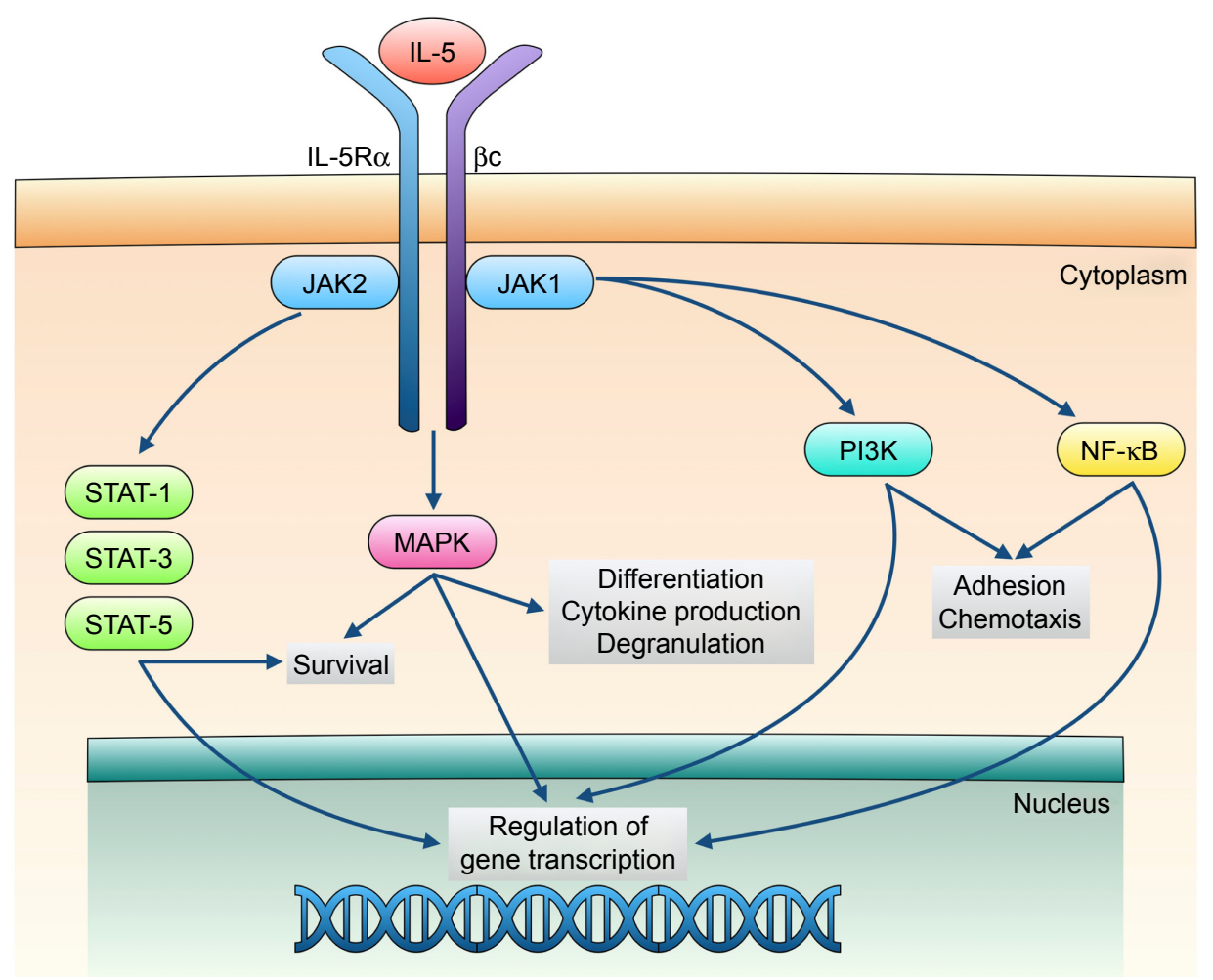

Figure I Signal transduction pathways underlying the biological actions exerted by IL-5 on eosinophils.

Notes: The interaction of IL- 5 with the $\alpha$ subunit of the IL-5 receptor (IL-5R $\alpha$ ) aggregates and stimulates the receptor complex consisting of both IL-5R $\alpha$ and $\beta c$ subunits. This event is responsible for the following involvement of multiple signaling pathways mediated by JAK/STAT interactions, as well as by activation of MAPK, PI3K, and NF- $\mathrm{B}$. The biologic actions of these kinases and transcription factors converge to induce the expression of key genes implicated in maturation, survival, degranulation, adhesion, and chemotaxis of eosinophils. See "IL-5 and eosinophilic asthma" section for additional information.

Abbreviations: IL-5, interleukin-5; JAK, Janus kinase; MAPK, mitogen-activated protein kinases; NF-KB, nuclear factor- $\mathrm{KB}$; PI3K, phosphoinositide 3-kinase; STAT, signal transducers and activators of transcription.

the anti-IL-5 antibody TRFK-5 abrogated the eosinophilic infiltration of the airways elicited by allergenic challenge. ${ }^{48}$ Furthermore, TRFK-5 suppressed airway eosinophilia and the correlated bronchial hyperresponsiveness experimentally induced in a monkey model of asthma. ${ }^{49}$ Subsequently, other biological drugs targeted to either IL-5 (mepolizumab and reslizumab) or its receptor (benralizumab) were developed and investigated in several clinical studies. ${ }^{16,50,51}$

\section{Efficacy and safety of mepolizumab as an add-on biological treatment for severe asthma}

Mepolizumab (SB-240563) is a humanized IgG1/k monoclonal antibody, which selectively binds with high affinity to IL-5 (Figure 2), thus preventing its interaction with IL-5R $\alpha .^{52-54}$ In particular, mepolizumab was generated by grafting antihuman IL-5 antigen recognition sites from murine origin onto a human IgG1 heavy chain. ${ }^{55}$ Mepolizumab target (ie, IL-5) is a 134-amino acid dimeric glycoprotein with a four-helix bundle motif, which consists of a $52-\mathrm{kDa}$ homodimer. ${ }^{56,57}$ Mepolizumab specifically binds to the $\alpha$-chain of IL-5 with an $\mathrm{IC}_{50}$ of $<1 \mathrm{nM}$, a dissociation constant of $4.2 \mathrm{pM}$, and a stoichiometry of 2.2, so that two IL-5 dimers are crosslinked by two molecules of mepolizumab. ${ }^{56,58}$ Therefore, via this mechanism of action, mepolizumab effectively inhibits

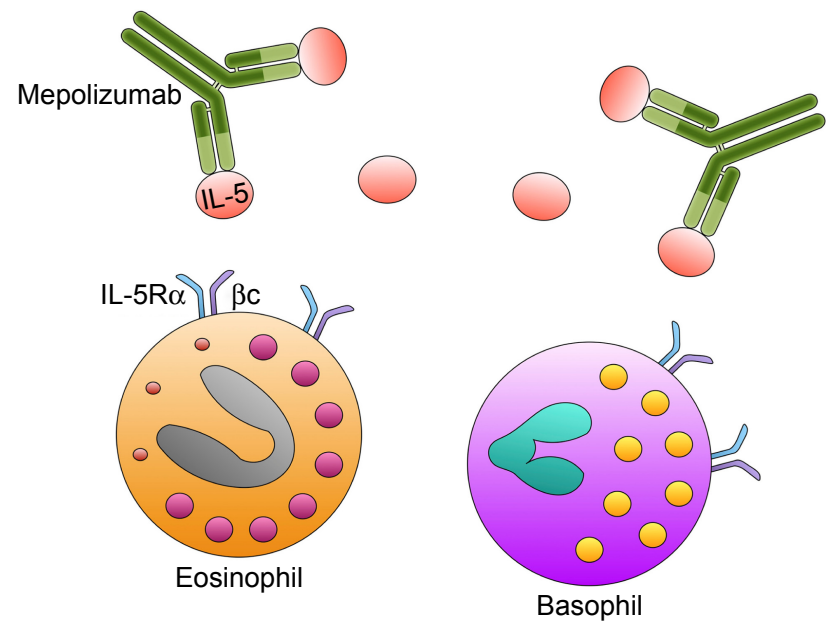

Figure 2 Mechanism of action of mepolizumab. Mepolizumab binds with high affinity to IL-5, thus preventing its interaction with the IL- 5 receptor expressed by eosinophils and, to a lesser extent, also by basophils.

Abbreviation: IL-5, interleukin-5. 
IL-5 ligation to IL-5R $\alpha$. This very specific binding pattern probably explains the relative lack of relevant side effects of mepolizumab. Indeed, because of its highly selective interaction with IL-5, mepolizumab does not appear to interfere with the biological activities of other cytokines.

Some early clinical trials, carried out in heterogeneous populations of patients with mild or moderate chronic persistent asthma, showed that mepolizumab significantly decreased eosinophil numbers in both blood and induced sputum. ${ }^{59-61}$ However, these effects were not associated with relevant changes in asthma symptoms, lung function, bronchial hyperresponsiveness, and activation status of $\mathrm{T}$ lymphocytes. In particular, when administered at a single intravenous dose of $10 \mathrm{mg} / \mathrm{kg}$, mepolizumab did not improve the late asthmatic reaction to allergen challenge and the bronchial response to histamine in subjects with mild asthma. ${ }^{59}$ Furthermore, in patients with moderate persistent asthma receiving a monthly intravenous dose of 250 or $750 \mathrm{mg}$ for 3 months, mepolizumab did not lower exacerbation rates, did not increase either forced expiratory volume in 1 second $\left(\mathrm{FEV}_{1}\right)$ or peak expiratory flow (PEF), and did not improve the overall quality of life (QoL). ${ }^{60}$

Subsequently, mepolizumab was evaluated by Haldar et al and Nair et al in small groups of subjects with carefully selected phenotypes of chronic severe asthma, characterized by recurrent exacerbations and bronchial eosinophilia refractory to both inhaled and systemic corticosteroids. ${ }^{62,63}$ Taken together, the results of these two small targeted trials showed that mepolizumab effectively reduced asthma exacerbations and eosinophil levels in both blood and induced sputum. In addition to these effects, given at a monthly intravenous dosage of $750 \mathrm{mg}$ for 4 months, mepolizumab also significantly decreased prednisone consumption and slightly enhanced $\mathrm{FEV}_{1}$ values. ${ }^{63}$ Further important information was gained by the longer study conducted by Haldar et al. ${ }^{62}$ In this trial, mepolizumab was delivered for 1 year through 12 monthly intravenous infusions of $750 \mathrm{mg}$. Chest imaging performed by CT (computed tomography) scans obtained before and after treatment demonstrated that when compared with placebo, mepolizumab significantly reduced airway wall thickness and total wall area. ${ }^{62}$ Therefore, these results suggest that mepolizumab can possibly affect bronchial remodeling, an airway structural feature that is especially relevant in severe asthma. Such findings thus confirmed previous observations reported by Flood-Page et al, who showed that mepolizumab was able to decrease the deposition of extracellular matrix proteins in the reticular basement membrane of bronchial mucosa and also to reduce the levels of transforming growth factor- $\beta 1$ (TGF- $\beta 1$ ) in bronchoalveolar lavage fluid (BALF). ${ }^{64}$ Hence, the potential anti-remodeling action of mepolizumab is very likely due to its capability of depleting eosinophils, which are prominent cellular sources of TGF- $\beta 1$, one of the most important growth factors contributing to airway structural changes in asthma. ${ }^{65}$

The results reported by Haldar and Nair have been further corroborated by the large, multicenter, Phase IIb/III DREAM (Dose Ranging Efficacy And safety with Mepolizumab in severe asthma) study, carried out by Nair et al in more than 600 patients with severe, exacerbation-prone and eosinophilic asthma, who were randomly assigned to four groups receiving at 4-week intervals 13 intravenous infusions of placebo or one of three doses of mepolizumab $(75,250$, or $750 \mathrm{mg}$ ). ${ }^{63}$ At all dosages used, mepolizumab effectively lowered blood and sputum eosinophil counts, as well as the frequency of asthma exacerbations by $39 \%-52 \%$, regardless of IgE levels and atopic status. ${ }^{66}$ However, no significant improvements in either asthma symptoms or lung function were detected. Interestingly, the enrolment criteria of this trial were based on the presence of a blood eosinophil count $>300$ cells $/ \mu \mathrm{L}$. Indeed, this inclusion parameter is easily and routinely measurable, thereby being much better assessable than the rather complex-to-perform cellular analysis of induced sputum, often not feasible in a real-life setting because of obvious requirements for a greater extent of technical and interpretative expertise. In addition, airway eosinophilic inflammation was also documented by one or more criteria at study entry or in the previous year, including a sputum eosinophil count of $\geq 3 \%$, a fractional exhaled nitric oxide (FeNO) concentration of $\geq 50 \mathrm{ppb}$ (parts per billion), or a quick deterioration of asthma control after a $25 \%$ or less reduction in regular maintenance therapy with inhaled or oral corticosteroids. An important finding of this study was the close relationship between blood eosinophil count and therapeutic efficacy. In particular, no efficacy was observed in patients with a blood eosinophil count $<150$ cells $/ \mu \mathrm{L}$. This result was instrumental in establishing entry criteria for the Phase III trials. The findings of DREAM study are consistent with those of a recent metaanalysis, referring to seven randomized and placebo-controlled studies, which investigated the effects of intravenous mepolizumab, thus concluding that this anti-IL-5 antibody decreased the risk of exacerbations and improved QoL in patients with eosinophilic asthma, but did not significantly affect symptoms and lung function. ${ }^{67}$

In 2014, the results of two other trials about the efficacy of mepolizumab in patients with severe eosinophilic asthma who had experienced more than two exacerbations in the previous 
year despite the use of high doses of inhaled corticosteroids, associated with additional anti-asthma drugs, were published. In particular, the double-blind Phase III SIRIUS (SteroId ReductIon with mepolizUmab Study) study was carried out by Bel et al in 135 patients with severe eosinophilic asthma requiring a daily oral corticosteroid therapy as maintenance treatment for at least 6 months. The patients were randomly assigned to receive either placebo or a low subcutaneous dose (100 mg) of mepolizumab every 4 weeks for 20 weeks. ${ }^{68}$ When compared with placebo, mepolizumab provided an oral glucocorticoid-sparing effect consisting of a $50 \%$ reduction of prednisone dosage. Moreover, mepolizumab also lowered asthma exacerbations and improved QoL and symptom control. The larger MENSA (MEpolizumab as adjunctive therapy iN patients with Severe Asthma) study was conducted by Ortega et al, who recruited 576 subjects with severe eosinophilic asthma on treatment with high doses of inhaled corticosteroids, aged between 12 and 82 years, and had experienced at least two exacerbations during the previous year, which required a systemic glucocorticoid therapy while they were receiving treatment with at least $880 \mu \mathrm{g} /$ day of fluticasone propionate or equivalents, as well as with at least 3 months of treatment including an additional controller drug. ${ }^{69}$ Moreover, all patients had to have an eosinophil count of at least 150 cells/ $\mu \mathrm{L}$ in peripheral blood at screening, and at least 300 cells/ $\mu \mathrm{L}$ at some time during the previous year. Furthermore, the enrolled patients were characterized by $\mathrm{FEV}_{1}$ values $<80 \%$ and $90 \%$ predicted for adults and adolescents under the age of 18 years, respectively. Other study requirements included $\mathrm{FEV}_{1}$ reversibility of $>12 \%$, and/or $\mathrm{FEV}_{1}$ variability $>20 \%$ between two clinical visits in the past 12 months, and/or a positive response to a bronchial challenge with either methacholine or mannitol during the previous year. In comparison with placebo, administration of mepolizumab every 4 weeks for 32 weeks, at dosages of $75 \mathrm{mg}$ intravenously or $100 \mathrm{mg}$ subcutaneously, induced significant decreases in asthma exacerbation rates of either $47 \%$ or 53\%, respectively. Moreover, both drug doses elicited significant improvements in QoL. Similar to SIRIUS study, the MENSA trial also documented a modest FEV increase. $^{68,69}$ Subsequently, mepolizumab was given subcutaneously, at a dosage of $100 \mathrm{mg}$ every 4 weeks for a further 52 weeks period, to 651 patients who had previously completed either SIRIUS or MENSA investigations. ${ }^{70}$ This open-label, Phase IIIb extension study, named COSMOS, showed that the clinical improvements induced by mepolizumab, including significant decreases in both annual rate of asthma exacerbations and daily intake of oral corticosteroids, were durable over time. ${ }^{70}$ More recently, the randomized, double-blind, placebo-controlled, Phase IIIb MUSCA study was carried out in 146 centers across the world. ${ }^{71}$ Five hundred and fiftyone subjects aged at least 12 years with severe eosinophilic asthma, who had experienced at least two exacerbations during the previous year, were randomly assigned to receive either $100 \mathrm{mg}$ of subcutaneous mepolizumab (274 patients) or placebo (277 patients) every 4 weeks for 24 weeks. Mepolizumab induced an early and prolonged improvement in patients' health-related quality of life (HRQOL) score, and this main finding was associated with relevant reductions in asthma exacerbations. ${ }^{72}$ Furthermore, post-hoc analyses of both SIRIUS and MENSA studies have recently shown, in patients with severe eosinophilic asthma, that mepolizumab treatment was effective at decreasing disease exacerbations and improving asthma control and QoL, regardless of previous use of the anti-IgE monoclonal antibody omalizumab. ${ }^{72}$ With regard to the comparative evaluation of the therapeutic effects of mepolizumab and omalizumab in patients with severe eosinophilic allergic asthma, eligible to receive both treatments, a recent systematic literature review suggests that mepolizumab is at least as effective as omalizumab in preventing asthma exacerbations and improving lung function. ${ }^{73}$

All these trials outlined a very good profile of safety and tolerability for mepolizumab, which resulted to be similar to placebo with regard to side effects and adverse events. ${ }^{74,75}$ The most common adverse events occurring during SIRIUS and MENSA studies were headache and nasopharyngitis. ${ }^{68,69}$ In addition, during the MENSA trial a slightly higher percentage of injection-site reactions were observed using mepolizumab subcutaneously $(9 \%)$, with respect to intravenous administration $(3 \%){ }^{69}$ The main aim of the COSMOS trial was to evaluate the long-term safety of mepolizumab; in particular, this study did not report any death or mepolizumab-related anaphylactic reaction. ${ }^{70}$ The development of neutralizing anti-mepolizumab antibodies is a very rare event, which has been only sporadically reported. ${ }^{76}$ The long-term safety of mepolizumab was also confirmed by an open-label study performed in 78 patients with hypereosinophilic syndromes, who experienced a good drug tolerance throughout a mean treatment period of 251 weeks. ${ }^{77}$

On the basis of the convincing evidence inferred from all these studies, in November 2015, mepolizumab became the first anti-cytokine biologic drug to be approved by the US Food and Drug Administration (FDA) as an add-on maintenance treatment for severe asthmatic patients, aged $\geq 12$ years, with a documented eosinophilic phenotype. 
Furthermore, mepolizumab has been recently included within the step 5 of GINA (Global Initiative for Asthma) guidelines as an add-on therapy for severe eosinophilic asthma, uncontrolled by standard treatments. ${ }^{6}$

\section{Concluding remarks}

A modern approach to treatment for severe asthma requires an accurate phenotypic characterization of asthmatic patients. In this regard, it is noteworthy that many subjects with eosinophilic asthma can be successfully treated with inhaled corticosteroids. However, despite the use of high dosages of these drugs, even when associated with recurrent and long-lasting courses of systemic corticosteroids, some patients with refractory eosinophilic asthma do not achieve an adequate control of their disease. Such subjects can thus significantly benefit from add-on biological therapies targeting IL-5, given the pivotal role played by this cytokine in inducing, maintaining, and amplifying airway eosinophilia. Within this context, mepolizumab is the most extensively evaluated anti-IL-5 monoclonal antibody, as well as the first one to be licensed for add-on treatment for severe eosinophilic asthma.

No direct comparative evaluation has been made between mepolizumab and either the other IL-5 inhibitor reslizumab, or the IL-5R $\alpha$ antagonist benralizumab. However, a recent global and indirect metaanalysis of 10 randomized placebocontrolled trials, involving 3,421 patients, demonstrated no clear superiority of one of these three biologic drugs when appropriate dosages were compared. ${ }^{78}$ Indeed, mepolizumab, reslizumab, and benralizumab provided similar patterns of persistent symptom control and exacerbation rate reduction in patients with severe eosinophilic asthma. Of course, headto-head trials should be performed to directly compare the beneficial effects of mepolizumab with those induced by reslizumab and benralizumab.

The very good efficacy and safety profile of mepolizumab, emerging from several premarketing randomized controlled trials, makes this biologic drug particularly suitable for a wide diffusion among patients with difficult-to-treat eosinophilic asthma. Therefore, it is likely that the near future will include meaningful data from real-world, postmarketing studies that will further corroborate the very promising therapeutic features of mepolizumab.

\section{Disclosure}

The authors report no conflicts of interest in this work.

\section{References}

1. Holgate ST, Wenzel S, Postma DS, et al. Asthma. Nat Rev Dis Primers. 2015;1:15025.
2. Pelaia G, Vatrella A, Busceti MT, et al. Cellular mechanisms underlying eosinophilic and neutrophilic airway inflammation in asthma. Mediators Inflamm. 2015(2015);Article ID 879783.

3. Ray A, Oriss TB, Wenzel SE. Emerging molecular phenotypes of asthma. Am J Physiol Lung Cell Mol Physiol. 2015;308(2):L130-L140.

4. Gauthier M, Ray A, Wenzel SE. Evolving concepts of asthma. Am J Respir Crit Care Med. 2015;192(6):660-668.

5. Fanta CH. Drug therapy: asthma. N Engl J Med. 2009;360(10): 1002-1014.

6. Global Initiative for Asthma (GINA). Global strategy for asthma management and prevention; 2017. Available from: http//www. ginasthma.org/. Accessed September 1, 2017.

7. Huber KL, Koessler K. The pathology of fatal asthma. Arch Intern Med. 1922;30:689-760.

8. Houston JC, De Navasquez S, Trounce JR. A clinical and pathological study of fatal cases of status asthmaticus. Thorax. 1953;8(3): 207-213.

9. Varricchi G, Bagnasco D, Borriello F, et al. Interleukin-5 pathway inhibition in the treatment of eosinophilic respiratory disorders: evidence and unmet needs. Curr Opin Allergy Clin Immunol. 2016;16(2): 186-200.

10. Haldar P. Patient profiles and clinical utility of mepolizumab in severe eosinophilic asthma. Biologics. 2017;11:81-95.

11. Bochner BS, Gleich GJ. What targeting eosinophils has taught us about their role in diseases. J Allergy Clin Immunol. 2010;126(1):16-25.

12. Bousquet J, Chanez P, Lacoste JY, et al. Eosinophilic inflammation in asthma. N Engl J Med. 1990;323(15):1033-1039.

13. Stirling RG, van Rensen EI, Barnes PJ, Chung KF. Interleukin-5 induces CD34+ eosinophil progenitor mobilization and eosinophil CCR3 expression in asthma. Am J Respir Crit Care Med. 2001;164(8 Pt 1): 1403-1409.

14. Fulkerson PC, Rothenberg ME. Targeting eosinophils in allergy, inflammation and beyond. Nat Rev Drug Discov. 2013;12(2):117-129.

15. Molfino NA, Gossage D, Kolbeck R, et al. Molecular and clinical rationale for therapeutic targeting of interleukin-5 and its receptor. Clin Exp Allergy. 2012;42(5):712-737.

16. Pelaia G, Vatrella A, Maselli R. The potential of biologics for the treatment of asthma. Nat Rev Drug Discov. 2012;11(12):958-972.

17. Gallelli L, Busceti MT, Vatrella A, et al. Update on anticytokine treatment for asthma. Biomed Res Int. 2013;2013:104315.

18. Patterson MF, Borish L, Kennedy JL. The past, present, and future of monoclonal antibodies to IL-5 and eosinophilic asthma: a review. J Asthma Allergy. 2015;8:125-134.

19. Bel EH, ten Brinke A. New anti-eosinophil drugs for asthma and COPD: targeting the trait. Chest. In press 2017.

20. Varricchi G, Bagnasco D, Ferrando M, et al. Mepolizumab in the management of severe eosinophilic asthma in adults: current evidence and practical experience. Ther Adv Respir Dis. 2017;11(1):40-45.

21. Woodruff PG, Modrek B, Choy DF, et al. T-helper type 2-driven inflammation defines major sub-phenotypes of asthma. Am J Respir Crit Care Med. 2009;180(5):388-395.

22. Smith SG, Chen R, Kjarsgaard M. Increased numbers of activated group 2 innate lymphoid cells in the airways of patients with severe asthma and persistent airway eosinophilia. J Allergy Clin Immunol. 2016; 137(1):75-86.

23. Shakoory B, Fitzgerald SM, Lee SA, et al. The role of human mast cell-derived cytokines in eosinophil biology. J Interferon Cytokine Res. 2004;24(5):271-281.

24. Sakuishi K, Oki S, Araki M, et al. Invariant NKT cells biased for IL-5 production act as crucial regulators of inflammation. J Immunol. 2007; 179(6):3452-3462.

25. Hogan SP, Rosenberg HF, Moqbel R, et al. Eosinophils: biological properties and role in health and disease. Clin Exp Allergy. 2008;38(5): 709-750.

26. Wood LJ, Sehmi R, Dorman S, et al. Allergen-induced increases in bone marrow $\mathrm{T}$ lymphocytes and interleukin-5 expression in subjects with asthma. Am J Respir Crit Care Med. 2002;166(6): 883-889. 
27. Dorman SC, Efthimiadis A, Babirad I, et al. Sputum CD34+ IL-5R $\alpha+$ cells increase after allergen: evidence for in situ eosinophilopoiesis. Am J Respir Crit Care Med. 2004;169(5):573-577.

28. Park SW, Kim DJ, Chang HS, et al. Association of interleukin-5 and eotaxin with acute exacerbation of asthma. Int Arch Allergy Immunol. 2003;131(4):283-290.

29. Xu J, Jiang F, Nayeri F, Zetterstrom O. Apoptotic eosinophils in sputum from asthmatic patients correlate negatively with levels of IL-5 and eotaxin. Respir Med. 2007;101(7):1447-1454.

30. Ilmarinen P, Moilanen E, Kankaanranta H. Regulation of spontaneous eosinophil apoptosis - a neglected area of importance. J Cell Death. 2014;7:1-9.

31. Brusselle GG, Maes T, Bracke KR. Eosinophilic airway inflammation in non allergic asthma. Nat Med. 2013;19(8):977-979.

32. Walker JA, Barlow JL, McKenzie AM. Innate lymphoid cells: how did we miss them? Nat Rev Immunol. 2013;13(2):75-87.

33. Rossjohn J, McKinstry WJ, Woodcock JM, et al. Structure of the activation domain of the GM-CSF/IL-3/IL-5 receptor common $\beta$-chain bound to an antagonist. Blood. 2000;95(8):2491-2498

34. Murphy JM, Young IG. IL-3, IL-5, and GM-CSF signaling: crystal structure of the human $\beta$-common receptor. Vitam Horm. 2006;74:1-30.

35. Kouro T, Takatsu K. IL-5- and eosinophil-mediated inflammation: from discovery to therapy. Int Immunol. 2009;21(12):1303-1309.

36. Johanson K, Appelbaum E, Doyle M, et al. Binding interactions of human interleukin 5 with its receptor $\alpha$ subunit. Large scale production, structural, and functional studies of Drosophila-expressed recombinant proteins. J Biol Chem. 1995;270(16):9459-9471.

37. Ishino T, Harrington AE, Gopi H, Chaiken I. Structure-based rationale for interleukin 5 receptor antagonism. Curr Pharm Des. 2008;14(12): 1231-1239.

38. Pazdrak K, Stafford S, Alam R. The activation of the Jak-STAT 1 signalling pathway by IL-5 in eosinophils. J Immunol. 1995;155(1): 397-402.

39. Stout BA, Bates ME, Liu LY, et al. IL-5 and granulocyte-macrophage colony-stimulating factor activate STAT3 and STAT5 and promote Pim-1 and cyclin D3 protein expression in human eosinophils. J Immunol. 2004;173(10):6409-6417.

40. Pazdrak K, Olszewska-Pazdrak B, Stafford S, et al. Lyn, Jak2, and Raf-1 kinases are critical for the antiapoptotic effect of interleukin-5, whereas only Raf-1 kinase is essential for eosinophil activation and degranulation. J Exp Med. 1998;188(3):421-429.

41. Adachi T, Alam R. The mechanism of IL-5 signal transduction. Am J Physiol. 1998;275(3 Pt 1):C623-C633.

42. Takatsu K, Nakajima H. IL-5 and eosinophilia. Curr Opin Immunol. 2008;20(3):288-294.

43. Bates ME, Green VL, Bertics PJ. ERK1 and ERK2 activation by chemotactic factors in human eosinophils is interleukin 5-dependent and contributes to leukotriene C4 biosynthesis. J Biol Chem. 2000; 275(15):10968-10975.

44. Pelaia G, Cuda G, Vatrella A, et al. Mitogen-activated protein kinases and asthma. J Cell Physiol. 2005;202(3):642-653.

45. Adachi T, Choudhuri BK, Stafford S, et al. The differential role of extracellular signal-regulated kinases and p38 mitogen-activated protein kinase in eosinophil functions. J Immunol. 2000;165(4): 2198-2204.

46. Ip WK, Wong CK, Wang CB, et al. Interleukin-3, -5, and granulocyte macrophage colony-stimulating factor induce adhesion and chemotaxis of human eosinophils via p38 mitogen-activated protein kinase and nuclear factor-кB. Immunopharmacol Immunotoxicol. 2005;27(3):371-393.

47. Sano M, Leff AR, Myou S, et al. Regulation of interleukin-5-induced $\beta 2$-integrin adhesion of human eosinophils by phosphoinositide 3-kinase. Am J Respir Cell Mol Biol. 2005;33(1):65-70.

48. Garlisi CG, Kung TT, Wang P, et al. Effects of chronic anti-interleukin-5 monoclonal antibody treatment in a murine model of pulmonary inflammation. Am J Respir Cell Mol Biol. 1999;20(2):248-255.

49. Mauser PJ, Pitman AM, Fernandez X, et al. Effects of an antibody to interleukin-5 in a monkey model of asthma. Am J Respir Crit Care Med. 1995;152(2):467-472.
50. Walsh GM. Therapeutic potential of targeting interleukin-5 in asthma. BioDrugs. 2013;27(6):559-563.

51. Pelaia G, Vatrella A, Busceti MT, et al. Role of biologics in severe eosinophilic asthma - focus on reslizumab. Ther Clin Risk Manag. 2016;12:1075-1082.

52. Gnanakumaran G, Babu KS. Technology evaluation: mepolizumab, GlaxoSmithKline. Curr Opin Mol Ther. 2003;5(3):321-325.

53. Walsh GM. Mepolizumab-based therapy in asthma: an update. Curr Opin Allergy Clin Immunol. 2015;15(4):392-396.

54. Fainardi V, Pisi G, Chetta A. Mepolizumab in the treatment of severe eosinophilic asthma. Immunotherapy. 2016;8(1):27-34.

55. Hart TK, Cook RM, Zia-Amirhosseini P, et al. Preclinical efficacy and safety of mepolizumab (SB-240563), a humanized monoclonal antibody to IL-5, in cynomolgus monkeys. J Allergy Clin Immunol. 2001;108(2): $250-257$.

56. Kusano S, Kukimoto-Niino M, Hino N, et al. Structural basis of interleukin-5 dimer recognition by its $\alpha$ receptor. Protein Sci. 2012; 21(6):850-864.

57. Abonia JP, Putnam PE. Mepolizumab in eosinophilic disorders. Expert Rev Clin Immunol. 2011;7(4):411-417.

58. Smith DA, Minthorn EA, Beerahee M, et al. Pharmacokinetics and pharmacodynamics of mepolizumab, an anti-interleukin-5 monoclonal antibody. Clin Pharmacokinet. 2011;50(4):215-227.

59. Leckie MJ, ten Brinke A, Khan J, et al. Effects of an interleukin-5 blocking monoclonal antibody on eosinophils, airway hyper-responsiveness, and the late asthmatic response. Lancet. 2000;356(9248):2144-2148.

60. Flood-Page P, Swenson C, Faiferman I, et al. A study to evaluate safety and efficacy of mepolizumab in patients with moderate persistent asthma. Am J Respir Crit Care Med. 2007;176(11):1062-1071.

61. Buttner C, Lun A, Splettstoesser T, et al. Monoclonal anti-interleukin-5 treatment suppresses eosinophil but not T-cell functions. Eur Respir J. 2003;21(5):799-803.

62. Haldar P, Brightling CE, Hargadon B, et al. Mepolizumab and exacerbations of refractory eosinophilic asthma. New Engl J Med. 2009; 360(10):973-984.

63. Nair P, Pizzichini MM, Kjarsgaard M, et al. Mepolizumab for prednisone-dependent asthma with sputum eosinophilia. New Engl J Med. 2009;360(10):985-993.

64. Flood-Page P, Menzies-Gow A, Phipps S, et al. Anti-IL-5 treatment reduces deposition of ECM proteins in the bronchial subepithelial basement membrane of mild atopic asthmatics. J Clin Invest. 2003;112(7): 1029-1036.

65. Makinde T, Murphy RF, Agrawall DK. The regulatory role of TGF- $\beta$ in airway remodeling in asthma. Immunol Cell Biol. 2007;85(5): $348-356$.

66. Pavord ID, Korn S, Howarth P, et al. Mepolizumab for severe eosinophilic asthma (DREAM): a multicentre, double-blind, placebocontrolled trial. Lancet. 2012;380(9842):651-659.

67. Liu Y, Zhang S, Li DW, Jiang SJ. Efficacy of antiinterleukin-5 therapy with mepolizumab in patients with asthma: a meta-analysis of randomized placebo-controlled trials. PLoS One. 2013;8(3):e59872.

68. Bel EH, Wenzel SE, Thompson PJ, et al; SIRIUS investigators. Oral glucocorticoid-sparing effect of mepolizumab in eosinophilic asthma. N Engl J Med. 2014;371(13):1189-1197.

69. Ortega HG, Liu MC, Pavord ID, et al; MENSA Investigators. Mepolizumab treatment in patients with severe eosinophilic asthma. N Engl J Med. 2014;371(13):1198-1207.

70. Lugogo N, Domingo C, Chanez P, et al. Long-term efficacy and safety of mepolizumab in patients with severe eosinophilic asthma: a multi-center, open-label, phase IIIb study. Clin Ther. 2016;38(9):2058-2070.

71. Chupp GL, Bradford ES, Albers FC, et al. Efficacy of mepolizumab add-on therapy on health-related quality of life and markers of asthma control in severe eosinophilic asthma (MUSCA): a randomized, doubleblind, placebo-controlled, parallel-group, multicenter, phase $3 \mathrm{~b}$ trial. Lancet Respir Med. 2017;5(5):390-400.

72. Magnan A, Bourdin A, Prazma CM, et al. Treatment response with mepolizumab in severe eosinophilic asthma patients with previous omalizumab treatment. Allergy. 2016;71(9):1335-1344. 
73. Cockle SM, Stynes G, Gunsoy NB, et al. Comparative effectiveness of mepolizumab and omalizumab in severe asthma: an indirect treatment comparison. Respir Med. 2017;123:140-148.

74. Menzella F, Lusuardi M, Galeone C, et al. Profile of anti-IL-5 mAb mepolizumab in the treatment of severe refractory asthma and hypereosinophilic disorders. J Asthma Allergy. 2015;8:105-114.

75. Leung E, Al Efraij K, Fitzgerald JM. The safety of mepolizumab for the treatment of asthma. Expert Opin Drug Saf. 2017;16(3):397-404.

76. Nair P. Anti-interleukin-5 monoclonal antibody to treat severe eosinophilic asthma. N Engl J Med. 2014;371(13):1249-1251.
77. Roufosse FE, Kahn JE, Gleich GJ, et al. Long-term safety of mepolizumab for the treatment of hypereosinophilic syndromes. J Allergy Clin Immunol. 2013;131(2):461-467.

78. Cabon Y, Molinari N, Marin G, et al. Comparison of anti-interleukin-5 therapies in patients with severe asthma: global and indirect metaanalyses of randomized placebo-controlled trials. Clin Exp Allergy. 2017;47(1):129-138.

\section{Publish your work in this journal}

Drug Design, Development and Therapy is an international, peerreviewed open-access journal that spans the spectrum of drug design and development through to clinical applications. Clinical outcomes, patient safety, and programs for the development and effective, safe, and sustained use of medicines are the features of the journal, which has also been accepted for indexing on PubMed Central. The manuscript management system is completely online and includes a very quick and fair peer-review system, which is all easy to use. Visit http://www.dovepress.com/testimonials.php to read real quotes from published authors.

Submit your manuscript here: http://www.dovepress.com/drug-design-development-and-therapy-journal 